\title{
First Peptide Vaccine Providing Protection against Viral Infection in the Target Animal: Studies of Canine Parvovirus in Dogs
}

\author{
JAN P. M. LANGEVELD, ${ }^{1 *}$ J. IGNACIO CASAL, ${ }^{2}$ ALBERT D. M. E. OSTERHAUS, ${ }^{3}$ ELENA CORTÉS, ${ }^{2}$ \\ RIK DE SWART, ${ }^{3}$ CARMEN VELA,${ }^{2}$ KRISTIAN DALSGAARD, ${ }^{4}$ WOUTER C. PUIJK, ${ }^{1}$ \\ WIM M. M. SCHAAPER, ${ }^{1}$ AND ROB H. MELOEN ${ }^{1}$ \\ Institute for Animal Science and Health, 8200 AB Lelystad, ${ }^{1}$ and Erasmus University, Rotterdam, 3015 CE Rotterdam, ${ }^{3}$ \\ The Netherlands; INGENASA, Inmunologia y Genetica Aplicada S.A., 28037 Madrid, Spain ${ }^{2}$; and \\ State Veterinary Institute for Virus Research, Lindholm, DK-4771 Kalvehave, Denmark ${ }^{4}$
}

Received 22 December 1993/Accepted 11 April 1994

\begin{abstract}
A synthetic peptide vaccine which protects dogs against challenge with virulent canine parvovirus is described. The amino acid sequence used was discovered in previous studies on the immunogenic properties of previously mapped antigenic sites and represents the amino-terminal region of viral protein VP2. As with marker vaccines, it is possible to discriminate between vaccinated dogs that have not been exposed to the virus and dogs that have been infected with the virus. The protective mechanism can be explained by a humoral response against the peptide aided by $T$-cell epitopes contained in the carrier protein used for peptide coupling. This is the first example of a synthetic peptide vaccine that induces protection in target animals.
\end{abstract}

Vaccines based on synthetic peptides would be safe and easy to produce. They would circumvent the risks in handling and spreading of the infectious agent inherent to conventional vaccines, and they would offer advantages over biologically produced vaccines, namely, reproducibility, exclusion of contaminating microorganisms, and stability. A considerable number of synthetic peptides which induce neutralizing antibodies $(4-6,16,23,25,41,54,55)$ and, to a variable extent, protection in the natural host $(14,15,20,22,26,35,38,50,52,56)$ have been described. However, none has yielded sufficient protection for application in a vaccination program. An important reason for this is that viral domains prone to neutralization behave as mutational hot spots, especially in RNA viruses (24, 53), with the small nonenveloped picornavirus foot-and-mouth disease virus and the complex retrovirus human immunodeficiency virus type 1 being extensively studied examples $(9,17$, $21,32)$. Although these data have led to the general belief that it is unrealistic to try to develop useful peptide vaccines, it remains theoretically possible that full protective responses could be achieved if the amino acid sequences used were based on parts of the viral particle that are not prone to mutation but are vital for its survival. We report here the validity of this assumption in canine parvovirus (CPV).

CPV is one of the autonomously replicating members of the Parvoviridae family, which are small (25-nm-diameter), nonenveloped, single-stranded DNA viruses (51). The DNA sequences of CPV and its highly homologous host range variants isolated from cats, minks, and raccoons appear to be conserved under field conditions (>98\% homology) $(33,36,37,42,43)$. The viral capsid is composed of 60 protein subunits, of which about $10 \%$ are VP1 and the remainder are VP2 and VP3 in variable proportions $(12,57)$. Proteins VP1 (748 amino acid residues) and VP2 (584 amino acid residues) are derived from the same gene by differential splicing, and VP3 is derived from VP2 by proteolytic removal of about 20 amino acids from the $\mathrm{N}$ terminus. Therefore, the entire amino acid sequences of

\footnotetext{
${ }^{*}$ Corresponding author. Mailing address: Institute for Animal Science and Health (ID-DLO), P.O. Box 65, Edelhertweg 15, $8200 \mathrm{AB}$ Lelystad, The Netherlands. Phone: 3200 73257. Fax: 320073473. Electronic mail address: LMI@CDI.AGRO.NL.
}

VP2 and VP3 are contained within the C terminus of VP1 (summarized in reference 12). While the spatial structure of most of the VP2 domain is known from X-ray diffraction analyses, the spatial structure of the amino-terminal 37 residues remains unknown because of its disordered state $(1,57)$. The amino acid sequences of this part of VP2 are completely identical in all CPV isolates and host range variants from cats, minks, and raccoons which have been analyzed $(33,37,42,43)$. The role and dynamics of the N terminus of VP2 in parvoviruses are subject to speculation. However, the domain is important because of the following observations. (i) Virus neutralization has been observed in vitro with a monoclonal antibody directed against this site (30). (ii) It is immunogenic in several animal species (27). (iii) It is involved in in vitro cell entry after the virus has attached to the membrane of the host cell (at least in the homologous parvovirus minute virus of mice [58]). The peptide vaccine described here is directed against a part of this site.

As with other parvoviruses, CPV replication is the most deleterious in actively dividing tissues (36). For dogs that do not have antibodies against the virus, the consequences of infection, namely, myocarditis in puppies less than 10 weeks old and severe enteritis later on, are devastating. Resistance against the disease is controlled by humoral immunity (for a review, see reference 36). We report here that in young dogs, effective protection of all animals (nine individuals tested) against canine parvovirus was obtained with a synthetic peptide vaccine. The selection of the sequence was based on a previous search for neutralization-inducing activity of synthetic peptides in rabbits (26a). The protective effect was provided by the antipeptide antibodies which appeared to be dependent on T-cell epitopes present in the carrier protein. To our knowledge, this is the first report of host protection induced by a synthetic peptide vaccine which can comply with requirements for practical application.

\section{MATERIALS AND METHODS}

Animals. New Zealand White rabbits were from Charles River (Sulzfeld, Germany). Specified-pathogen-free (SPF) fe- 
male beagle dogs were obtained from Harlan CPB, Zeist, The Netherlands.

Materials. 9-Fluorenylmethoxycarbonyl (Fmoc) amino acids and 4-(2',4'-dimethoxyphenyl-Fmoc-aminomethyl)-phenoxy resin (hereafter called Rink resin) (47) were purchased from Saxon Biochemicals (Hannover, Germany), benzotriazole-1-yl-oxy-tris-(pyrrolidino)phosphonium hexafluorophosphate (PyBOP) was from Novabiochem (Laufelfingen, Switzerland), and $m$-maleimidobenzoic acid- $N$-hydroxysuccinimide ester (MBS) was from Sigma (St. Louis, Mo.). Keyhole limpet hemocyanin (KLH) in the crystalline form was from Calbiochem (La Jolla, Calif.), goat anti-dog immunoglobulin (Ig) peroxidase conjugate was from Cappel (West Chester, Pa.), and swine anti-rabbit Ig peroxidase and rabbit anti-mouse Ig peroxidase conjugates were from DAKO (Glostrup, Denmark). QuilA was prepared as previously described (13). Aluminium hydroxide gel was a gift from S. J. Barteling (Institute for Animal Science and Health, Lelystad, The Netherlands). Complete and incomplete Freund's adjuvant were from Difco Laboratories (Detroit, Mich.). Other solvents and reagents used were of analytical grade.

Virus and cells. CPV strain CPV-c/780916 used in an enzyme-linked immunosorbent assay (ELISA) for anti-CPV antibody detection was obtained from the American Type Culture Collection (VR-953) and propagated on feline kidney cells (CRFK) (ATCC CCL94) and purified as previously described (27). Challenge virus (a gift from A. Fernandez, University of Cordoba, Cordoba, Spain) was obtained by extraction from the feces of a mongrel dog that died from CPV infection. Virus was extracted with tissue culture medium and then treated with chloroform by established procedures (7). The extract was passed through a $0.22-\mu \mathrm{m}$ pore-size filter under sterile conditions and stored at $-20^{\circ} \mathrm{C}$ until used.

Peptides. Two peptides, 1L15 and 7L15, with the partially overlapping sequences MSDGAVQPDGGQPAV and QPDG GQPAVRNERAT, respectively, were used in this study. They were synthesized on Rink resin $(0.1-\mathrm{mmol}$ scale, $0.48 \mathrm{mil}-$ liequivalent/g). Couplings were carried out with Fmoc-amino acids ( 3 equivalents) in the presence of PyBOP ( 3 equivalents), $N$-hydroxybenzoltriazole ( 3 equivalents), and diisopropylethylamine (6 equivalents). The procedures for synthesis and deprotection were based on established methods $(11,47)$. The syntheses were performed either manually in glass vessels or on an Applied Biosystems 430A synthesizer using Fastmoc chemistry (19). Peptides were synthesized with a cysteine at the amino terminus for coupling with KLH and with the $\mathrm{N}$ and $\mathrm{C}$ termini in the acetylated and amidated forms, respectively, and were analyzed by high-performance liquid chromatography on a C18 reversed-phase column (150 by $4.6 \mathrm{~mm}$; bead diameter, $5 \mu \mathrm{m}$; Supelcosil LC-18-DB; Supelco) using photodiode array detection. A linear gradient of methanol from 10 to $80 \%$ $(1 \% / \mathrm{min})$ in $0.1 \%$ trifluoroacetic acid in water at $30^{\circ} \mathrm{C}$ at a flow rate of $1 \mathrm{ml} / \mathrm{min}$ was used. Peptides were purified on a C18 reversed-phase column ( 2 by $25 \mathrm{~cm}$; Bischoff Präp 2025). Methanol gradients with a rise of $1 \%$ methanol per min at a flow rate of $10 \mathrm{ml} / \mathrm{min}$ in water and $0.1 \%$ (vol/vol) trifluoroacetic acid were used. Amino acid analysis was performed both before and after purification according to the procedures for Picotag (Waters, Milford, Mass.).

Conjugation of peptides. Coupling of purified peptides to KLH was performed by standard procedures with MBS as a linking agent (28). In the conjugation procedure, dialysis, instead of gel filtration, was used. After attachment of the linker to $\mathrm{KLH}, 1 \mathrm{mg}$ of peptide was added per $\mathrm{mg}$ of $\mathrm{KLH}$ (protein content was determined by amino acid analysis), and the mixture was incubated overnight at room temperature. For the vaccine, the conjugates were used in the nondialyzed form. The efficiency of coupling was checked by amino acid analysis of dialyzed aliquots for each peptide and varied between 80 to $300 \mu \mathrm{g}$ of peptide per mg of KLH.

Vaccination and immunization. A mixture of two nondialyzed KLH-peptide conjugates (peptides 1L15 and 7L15, $1 \mathrm{mg}$ each was injected into dogs and rabbits. This mixture $(0.6 \mathrm{ml})$ plus $50 \mu \mathrm{g}$ of QuilA was adsorbed to $1 \mathrm{~g}$ of aluminium hydroxide gel (final volume, $1.6 \mathrm{ml}$ ). Two consecutive vaccination experiments were performed with 3 dogs in the first experiment and 10 dogs in the second experiment (Table 1). The animals received the preparations by subcutaneous injection on days 1 and 30 . Control dogs received placebo preparations containing amounts of $\mathrm{KLH}$, QuilA, and aluminium hydroxide equivalent to those used for the vaccinated dogs. On day 72 , the animals were exposed to challenge with CPV on their eyes, noses, and mouths $(2.5 \mathrm{ml})$. The condition, eating habits, and rectal temperatures of the dogs were monitored weekly or, during the experimental infection, daily. Blood samples for preparation of serum and peripheral blood mononuclear cells (PBMC) were collected at various times before and during vaccination and after challenge. For immunization of rabbits as reference animals, the immunization cocktail (total volume, $2 \mathrm{ml}$ ) consisted of the same mixture of $\mathrm{KLH}$ conjugated peptides $1 \mathrm{~L} 15$ and $7 \mathrm{~L} 15$ as used in the dogs, adsorbed to aluminium hydroxide plus QuilA, and was administered by subcutaneous and intramuscular routes. On day 42 , the animals received a second injection of the same cocktail.

Peptide ELISA for detection of peptide-specific antibodies and PEPSCAN. For peptide ELISA, all incubations were carried out with $100-\mu$ l volumes in the wells of polystyrene microtiter plates and washes were performed between each step with $0.05 \%$ (wt/vol) Tween 80 in phosphate-buffered saline (PBS). The wells of polystyrene plates (Greiner, 665101) were coated with peptides overnight at $4^{\circ} \mathrm{C}$ at $10 \mu \mathrm{g} / \mathrm{ml}$ in 50 $\mathrm{mM}$ Na-carbonate solution, $\mathrm{pH}$ 9.6. For incubation with the first antibody, rabbit or dog sera were diluted in incubation buffer, which consisted of $4 \%$ (vol/vol) horse serum, $1 \%$ (wt/vol) Tween 80 , and $0.5 \mathrm{M} \mathrm{NaCl}$ in PBS, and incubated for $1 \mathrm{~h}$ at $25^{\circ} \mathrm{C}$. The second antibody incubation was at $25^{\circ} \mathrm{C}$ with anti-rabbit or anti-dog Ig peroxidase diluted 1/1,000 in incubation buffer. Color was developed with tetramethylbenzidine and stopped after $20 \mathrm{~min}$ with $\mathrm{H}_{2} \mathrm{SO}_{4} . A_{450}$ was measured.

Sera from dogs were tested with a PEPSCAN procedure as previously described, using the same set of solid-phase nonapeptides representing the entire 748 residues of VP1 (27).

ELISA for detection of CPV-specific antibodies. Two different methods were used to detect CPV-specific antibodies: an indirect and a competitive anti-CPV ELISA. For the indirect anti-CPV ELISA, the wells of plates (Polysorb; Nunc, Roskilde, Denmark) were coated with purified CPV at $1 \mu \mathrm{g} / \mathrm{ml}$ in $0.5 \mathrm{M}$ Na-carbonate buffer $\left(\mathrm{pH} \mathrm{9.6)}\right.$ overnight at $4^{\circ} \mathrm{C}$. Washes between consecutive steps were carried out with $0.05 \%$ (wt/ vol) Tween 20 in physiological saline (Tween-saline). Coated plates were incubated for $2 \mathrm{~h}$ at $37^{\circ} \mathrm{C}$ with dog or rabbit sera diluted in $2 \%$ (wt/vol) bovine serum albumin in Tween-saline. After the plates were washed, they were further incubated with anti-rabbit or anti-dog Ig peroxidase conjugate in $2 \%(\mathrm{wt} / \mathrm{vol})$ bovine serum albumin in Tween-saline for $1 \mathrm{~h}$ at ambient temperature. Color was developed with $100 \mu$ l of $o$-phenylenediamine $(1 \mathrm{mg} / \mathrm{ml})$ in a solution of $24.3 \mathrm{mM}$ citric acid, $51.4 \mathrm{mM} \mathrm{Na}_{2} \mathrm{HPO}_{4}$, and $0.012 \%$ (vol/vol) $\mathrm{H}_{2} \mathrm{O}_{2}$ and within 30 min stopped by the addition of $50 \mu \mathrm{l}$ of $1.5 \mathrm{M} \mathrm{H}_{2} \mathrm{SO}_{4} . A_{495}$ was measured.

Competitive anti-CPV ELISA was performed as previously 
described (46). In this assay, plates coated with CPV antigen were incubated with a mixture of dog serum samples (at different concentrations) and a constant amount of CPVspecific monoclonal antibodies conjugated to horseradish peroxidase.

DAS ELISA for the detection of CPV antigen. The presence of CPV antigen in fecal samples was investigated with doubleantibody sandwich (DAS) ELISA as previously described (46).

In vitro neutralization and hemagglutination inhibition (HI). Neutralizing activity of sera was determined by assaying the CRFK cell monolayer protection activity as previously described (30). In neutralization blocking experiments, undiluted serum samples were incubated with an equal volume of culture medium with or without peptides 1 L15 plus 7L15 (final concentration of peptides was $100 \mu \mathrm{M}$ [each]). The samples were further diluted in series starting from a serum dilution of $1 / 40$, mixed with 100 hemagglutination units of CPV, and incubated for $2 \mathrm{~h}$ at $37^{\circ} \mathrm{C}$. Finally, cells were inoculated with these mixtures and incubated according to the standard monolayer protection protocol.

HI tests were performed with African green monkey (Cercopithecus aethiops) erythrocytes as previously described (46).

Proliferative assays for dog PBMC. Heparinized blood samples were collected from dogs in the second vaccination experiment. PBMC were isolated by sedimentation of blood samples on Lymphoprep (Nycomed, Oslo, Norway). Except for the PBMC obtained at the end of the experiment (90 days postinfection [dpi]), the cells were kept frozen at $-135^{\circ} \mathrm{C}$ in Iscove's modified Dulbecco's medium (IMDM) supplemented with $20 \%$ heat-inactivated fetal calf serum and $10 \%$ methyl sulfoxide. For proliferative assays, PBMC were thawed and cultured in 96-well round-bottom culture microtiter plates with $10^{5}$ cells per well in IMDM supplemented with penicillin $(100$ $\mathrm{IU} / \mathrm{ml})$, streptomycin $(100 \mu \mathrm{g} / \mathrm{ml})$, L-glutamine $(2 \mathrm{mM}), \beta$-mercaptoethanol $\left(2 \times 10^{-2} \mathrm{mM}\right)$, and $10 \%$ heat-inactivated SPF dog sera (negative for CPV antibodies). In addition, fresh autologous gamma-irradiated (with 3,000 rads) PBMC, isolated at 90 dpi after immunization, were added as feeder cells at a concentration of $1.5 \times 10^{6}$ cells per well. The vitality of PBMC was checked by stimulation with the T-cell mitogen concanavalin A $(5 \mu \mathrm{g} / \mathrm{ml})$, which consistently resulted in stimulation indices of over 50 (not shown). Stimulation was performed with synthetic peptides $(5 \mu \mathrm{g} /$ well $)$, peptide-KLH conjugate as used for vaccination of dogs $(2.5 \mu \mathrm{g}$ [each] of two conjugates per well), KLH (5 $\mu \mathrm{g} /$ well), and purified CPV $(0.3$ $\mu \mathrm{g} /$ well) inactivated with $\beta$-propiolactone. PBMC were cultured for 6 days; to increase the proliferation activity of the stimulated cells, on day 5 , recombinant human interleukin-2 (2 U/well) (Boehringer, Mannheim, Germany) was added to those cultures that were started from thawed cells. During the last $16 \mathrm{~h}$ of culture, PBMC were pulse-labeled with $0.5 \mu \mathrm{Ci}$ of $\left[{ }^{3} \mathrm{H}\right]$ thymidine per well, and cell-associated radioactivity was counted. Results were obtained from triplicate assays and expressed as stimulation indices which represent the ratio of counts per minute of stimulated and control (medium only) cultures.

\section{RESULTS}

Vaccine composition and vaccination. Two pentadecapeptides, $1 \mathrm{~L} 15$ and 7L15, with the overlapping sequences MSD GAVQPDGGQPAV and QPDGGQPAVRNERAT, respectively (see Materials and Methods), were included in the vaccine. Their sequences represent the first 21 amino acids of the amino terminus of the major capsid protein VP2 of CPV. This choice was based on previous studies on epitope mapping
$(27,30)$ and subsequent immunization of rabbits with a set of peptides to further delineate the functional core of antigenic sites (26a). It was shown that these two peptides could be used to induce antibodies with in vitro neutralizing capacity.

Young, age-matched, and SPF dogs were injected with one dose of the vaccine on days 1 and 30 (Table 1). A vaccine dose contained a mixture of $1 \mathrm{mg}$ of peptide $1 \mathrm{~L} 15$ and $1 \mathrm{mg}$ of peptide 7L15, with each peptide separately conjugated to $\mathrm{KLH}$. On day 72, the animals were challenged with CPV by the oronasal and ocular routes. Two similar but completely separate vaccination experiments were performed, with newly prepared and purified peptides. These two independent experiments with 3 and 10 dogs, respectively, yielded similar results.

Course of antibody production by vaccination. In all vaccinated animals, antipeptide and anti-CPV antibody titers were nearly maximal at 2 weeks after the first immunization, rose marginally within the next 10 days after the booster injection, and then gradually declined (Fig. 1a and b). Serum neutralizing activity in the first vaccination experiment, as measured by monolayer protection test, also appeared within 2 weeks and was maximal between weeks 3 and 6 , but then the titers dropped below the detection level in the remaining preinfection period (Fig. 1c). In the second experiment, none of the dogs developed detectable in vitro neutralizing activity before challenge (not shown). The control dogs remained seronegative until seroconversion $6 \mathrm{dpi}$ (Fig. $1 \mathrm{~b}$ and c).

Protection against challenge. Experimental exposure with a fecal CPV preparation led to severe infection of all four control dogs (Table 1), while the vaccinated animals remained clinically healthy. The clinical signs in the control dogs were anorexia, weakness, diarrhea, and severe intestinal hemorrhage (blood in the stool), which are typical CPV manifestations (39). The results of histologic examinations of these dogs were in accordance with parvovirus infection. Analysis of extracts from the intestinal tract for the presence of CPV by established procedures (45) showed that the infection was caused by CPV and not by other agents (e.g., canine coronavirus). Of the four control dogs, one died at $6 \mathrm{dpi}$, another died the next day, and the remaining two were euthanized on the same day to stop further suffering. No anti-CPV antibodies could be detected in any of the serum samples of the control dogs except from 6 dpi (Fig. 1). Massive excretion of CPV in the feces of these dogs was observed at 4 and $5 \mathrm{dpi}$, while in four of nine vaccinated dogs, only a very low level of CPV on 5 dpi was found (Fig. 2). Body temperatures were elevated in all control dogs on 4 dpi (above the normal fluctuation maximum of $39.6^{\circ} \mathrm{C}$ ) and in five of nine vaccinated animals on 5 or $6 \mathrm{dpi}$. Although this is an indicator for CPV infection (39), none of the dogs vaccinated with the peptide vaccine became clinically ill or showed any sign of disease, including loss of appetite. Therefore, the vaccine efficiently protects dogs against infection with virulent CPV.

Neutralization blocking experiments. The induction of in vitro neutralizing activity in both nonvaccinated and vaccinated dogs shortly after challenge (6 to $10 \mathrm{dpi}$ [Fig. 1]), suggested the occurrence of an additional class of neutralizing antibodies directed to epitopes other than the linear neutralization site in the VP2 $\mathrm{N}$ terminus. This was confirmed with neutralizing antisera of dogs from the first vaccination experiment by preincubation with the peptides used for vaccination (Table 2). Before challenge, neutralizing activity in sera from vaccinated dogs could be completely blocked. However, after challenge, no blocking by the peptides was observed.

T-cell proliferation. The protective effect of vaccination with peptides conjugated to KLH raised the question about the origin of T-cell epitopes mediating the humoral response. The 
$\log [$ titer]
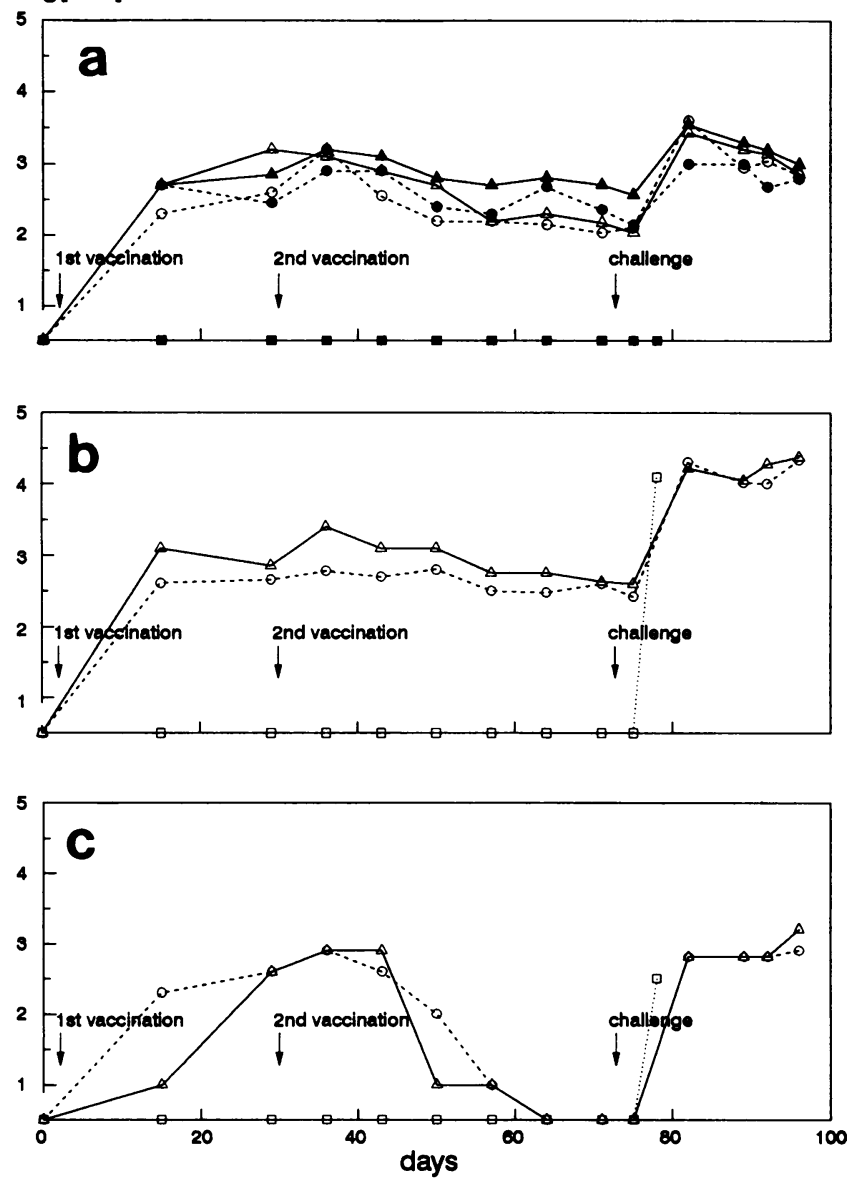

FIG. 1. Course of antibody production in dogs vaccinated with synthetic peptides. The results are given for the three dogs from experiment 1 of which one $(\operatorname{dog} 3)$ received a placebo (Table 1$)$. (a) Peptide ELISA for detection of antipeptide antibodies with either peptide 1L15 (closed symbols) or 7L15 (open symbols) as the coated antigen; (b) indirect CPV ELISA for detection of anti-CPV antibodies; (c) virus neutralization test based on in vitro monolayer protection. Symbols: $\square$, control dog (dog 3); $\triangle$, vaccinated dog $1 ; \bigcirc$, vaccinated $\operatorname{dog} 2$. The control dog in this experiment died $6 \mathrm{dpi}$. In each test, the lowest dilution analyzed was $1 / 10$. Titers in an ELISA were taken at those serum dilutions which yielded absorption values four times the blank (preimmunization serum) value. Panels a and $b$ are representative for both vaccination experiments.

proliferative activity of PBMC in vaccinated animals was assayed as $\left[{ }^{3} \mathrm{H}\right]$ thymidine incorporation at the following five times: before vaccination, before challenge, and after infection at 9, 30, and 90 dpi (Fig. 3). Before and after challenge, T-cell activity was observed when KLH was present as the antigen, either free or conjugated to the peptides. After challenge, CPV antigen was also able to induce a T-cell response, but this was only obvious from $30 \mathrm{dpi}$ on (while antibody titers were already elevated at 8 dpi [Fig. 1 and 3]). The peptides themselves did not induce any proliferation.

Discrimination between vaccinated and infected animals. Many viruses including CPV are able to agglutinate erythrocytes which are reported to have distinct receptors for such viruses, albeit these receptors are not necessarily the same as those involved in infection of target cells. Antisera against these viruses are often capable of inhibiting hemagglutination
TABLE 1. Vaccination of dogs against canine parvovirus ${ }^{a}$

\begin{tabular}{cccc}
\hline Expt & $\begin{array}{c}\text { Age (wk) at } \\
\text { 1st injection }\end{array}$ & $\begin{array}{c}\text { Injected } \\
\text { material }^{b}\end{array}$ & $\begin{array}{c}\text { No. of dogs protected/ } \\
\text { no. of dogs injected }\end{array}$ \\
\hline 1 & 13 & Vaccine & $2 / 2$ \\
& & Placebo & $0 / 1$ \\
2 & 15 & Vaccine & $7 / 7$ \\
& & Placebo & $0 / 3$ \\
\hline
\end{tabular}

${ }^{a}$ Two similar vaccination experiments were performed at different times with newly prepared peptides. In the first experiment, three 13-week-old female dogs were kept in separate cages and one of the dogs served as a control. In the second experiment, 10 15-week-old animals (4 females and 6 males) were used, housed in three groups and one group (one female and two males) served as a control group.

${ }_{b}^{b}$ Each dose of the vaccine contained $1 \mathrm{mg}$ each of peptides $1 \mathrm{~L} 15$ and $7 \mathrm{~L} 15 ; 80$ to $300 \mu \mathrm{g}$ of each peptide was covalently bound to KLH, as determined by amino acid analysis (see also Materials and Methods).

activity (HI). In general, CPV neutralizing antibodies also have $\mathrm{HI}$ activity, but one monoclonal anti-CPV antibody (3C9) with a strong neutralizing effect does not. This antibody was shown to bind to the sequence QPAVR within the $21 \mathrm{~N}$-terminal residues of VP2 (27). The neutralizing antipeptide antibodies from vaccinated dogs taken before challenge did not have $\mathrm{HI}$ activity (Table 3 ), and the neutralizing rabbit antipeptide sera also did not have HI activity (not shown). The challenge with virus induced $\mathrm{HI}$ activity from $6 \mathrm{dpi}$ on in vaccinated dogs and also control dogs. Thus, with an HI assay and ELISA (Table 3; Fig. 1), it is possible to discriminate between animals which had been vaccinated with the synthetic peptide vaccine and were not exposed to the virus (positive only by ELISA) and animals which had been infected (positive by both ELISA and $\mathrm{HI})$.

Sequence specificity of antibodies from vaccinated dogs. Previously, a linear site (SDGAVQ at positions 2 to 7 of VP2) was recognized by three (of six) serum samples from dogs naturally infected with CPV when analyzed in a PEPSCAN on solid-phase synthetic peptides (27). This group of serum samples was later extended with 12 other serum samples from naturally infected dogs, but none of these serum samples

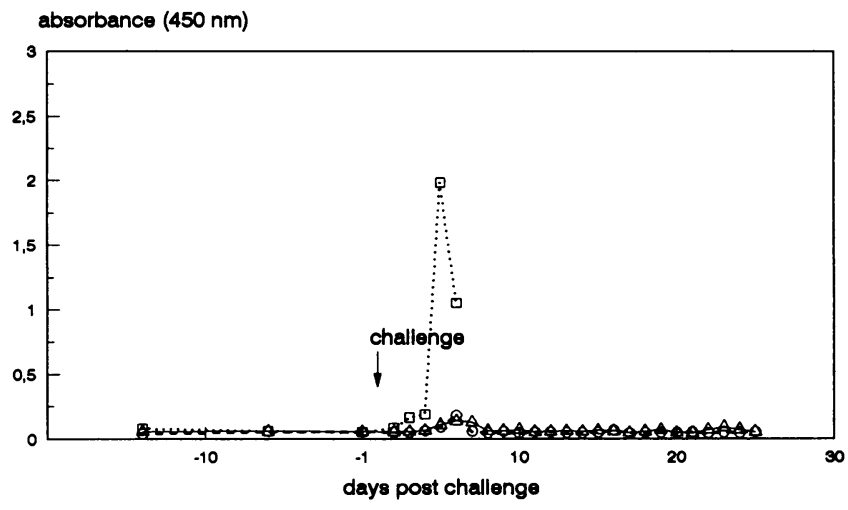

FIG. 2. Viral excretion in dog feces in vaccination experiment with synthetic peptides. Analysis of samples from experiment 1 (Table 1) is shown. The analyses of experiment 2 exhibited exactly the same features: three control animals had high fecal CPV content on day 4 (absorbance values above 2), while of the seven vaccinated animals, five had no detectable excretion and two had low absorbance values (0.13 and 0.32 ) on $5 \mathrm{dpi}$ only. The presence of CPV antigen was determined by DAS ELISA. Symbols are as defined in the legend to Fig. 1. 
TABLE 2. Blocking of in vitro neutralization with peptides ${ }^{a}$

\begin{tabular}{|c|c|c|c|c|c|c|}
\hline \multirow{4}{*}{ Experimental timing } & \multicolumn{6}{|c|}{ Neutralization titer ${ }^{b}$} \\
\hline & \multicolumn{4}{|c|}{ Vaccinated } & \multirow{2}{*}{\multicolumn{2}{|c|}{$\begin{array}{c}\text { Nonvacci } \\
\text { nated } \\
\operatorname{dog} 3\end{array}$}} \\
\hline & \multicolumn{2}{|c|}{$\operatorname{Dog} 1$} & \multicolumn{2}{|c|}{ Dog 2} & & \\
\hline & + & - & + & - & + & - \\
\hline Before immunization (day 0) & $<$ & $<$ & $<$ & $<$ & $<$ & \\
\hline After 2 nd vaccination (day 43 ) & $<$ & 800 & $<$ & 800 & $<$ & \\
\hline After challenge (6-10 dpi) & 800 & 800 & 1,600 & 1,600 & 800 & 800 \\
\hline
\end{tabular}

a Sera were taken from dogs in experiment 1 (Table 1).

${ }^{b}$ Values are given as titers of neutralization determined in monolayer protection test. Symbols: + and - indicate incubation with and without peptides $1 \mathrm{~L} 15$ plus 7L15, respectively (see also Materials and Methods); <, no detectable neutralizing activity (the lowest dilution measured was $1 / 10$ ).

bound to sequences in the N-terminal domain of VP2. These results indicate that the domain is not an immunodominant site on the virus. On the other hand, the sera from the dogs vaccinated with the peptides, taken either before or after the challenge, bound to the $\mathrm{N}$-terminal domain at another site (DGGQPAVR at positions 9 to 16 of VP2) (Fig. 4).

\section{DISCUSSION}

In this report the first synthetic peptide vaccine which yields protection in the target animal is described. Protection in dogs was obtained with two overlapping peptides representing the 21-residue-long $\mathrm{N}$ terminus of VP2 of canine parvovirus. The
TABLE 3. Differentiation between vaccinated and infected dogs ${ }^{a}$

\begin{tabular}{|c|c|c|c|c|c|c|}
\hline \multirow{3}{*}{$\begin{array}{l}\text { No. of days after } \\
\text { immunization }\end{array}$} & \multicolumn{6}{|c|}{ Titer } \\
\hline & \multicolumn{3}{|c|}{$\mathrm{HI}^{c}$} & \multicolumn{3}{|c|}{ ELISA $^{d}$} \\
\hline & Dog 1 & $\operatorname{Dog} 2$ & Dog 3 & Dog 1 & Dog 2 & Dog 3 \\
\hline \multicolumn{7}{|l|}{ Before challenge } \\
\hline 0 & $<$ & $<$ & $<$ & $<$ & $<$ & $<$ \\
\hline 71 & $<$ & $<$ & $<$ & 320 & 160 & $<$ \\
\hline \multicolumn{7}{|l|}{ After challenge } \\
\hline 82 & 4,096 & 4,096 & $4,096^{e}$ & 5,120 & 5,120 & $2,560^{\circ}$ \\
\hline 96 & 4,096 & 2,048 & & 10,240 & 10,240 & \\
\hline
\end{tabular}

"Sera from the first experiment with two vaccinated dogs (dogs 1 and 2) and one control $\operatorname{dog}(\operatorname{dog} 3)$ were taken on the indicated day. Challenge with virus occurred on day 72 .

${ }^{b}$ The results of the two immunochemical tests are expressed as titers. $<$, below the detection level.

' In the HI assay, the lowest dilution tested was $1 / 4$. In experiment $2, \mathrm{H}$ activity (titer of $>16$ ) also started to appear from 6 dpi on in all animals (not shown).

"In the competitive CPV ELISA, the lowest serum dilution tested was 1/40.

" These samples were taken at day 78 because dog 3 died at day 78 (6 dpi).

protection obtained in two different experiments was reproducible and effective in all vaccinated individuals (nine of nine), even though the CPV preparation used for challenge infection was highly virulent, causing severe disease in all four control animals which succumbed as a result of infection. The reason for this success can probably be attributed to a combination of the following factors. (i) The N-terminal domain of
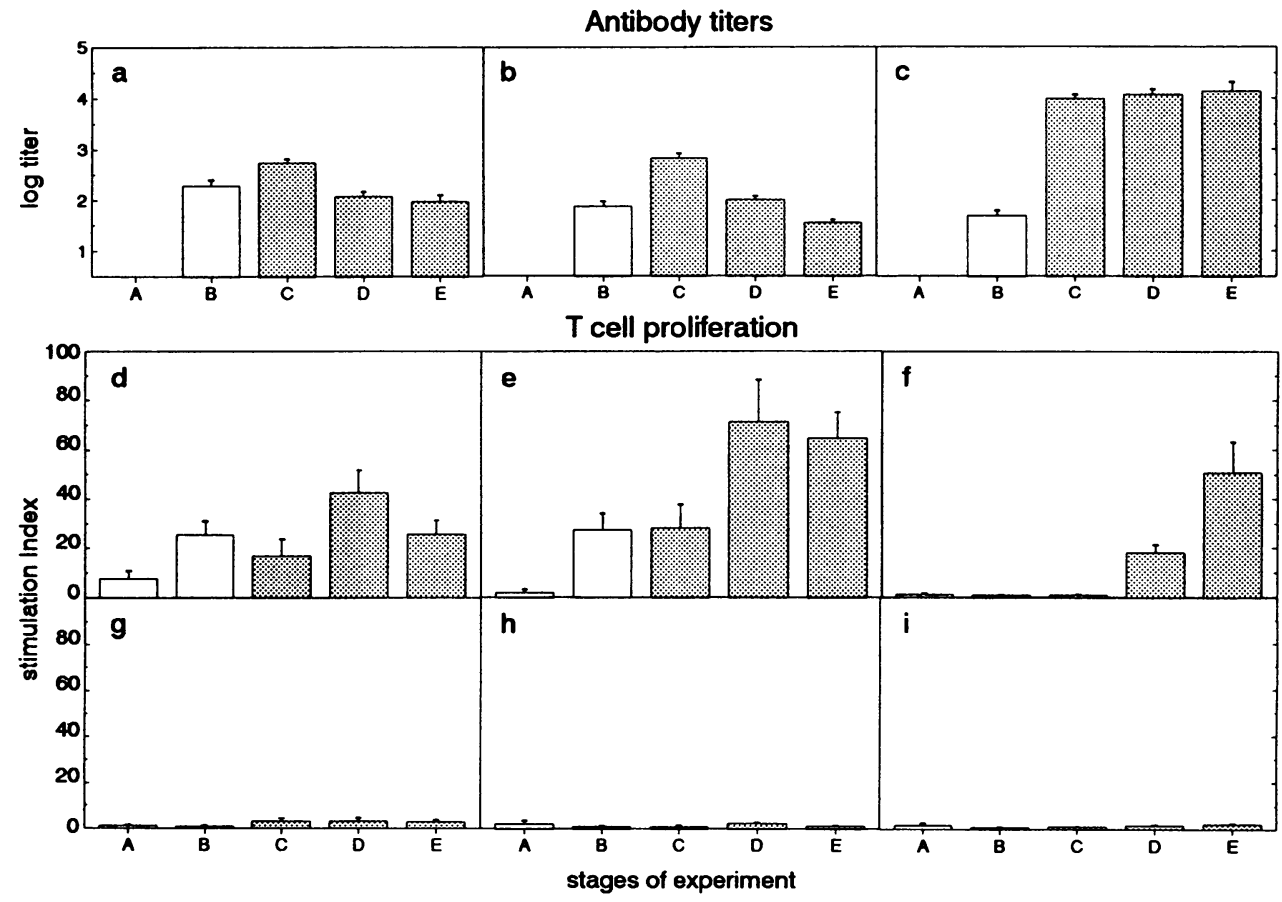

FIG. 3. Antibody titer and T-cell activity in dogs vaccinated with the peptide vaccine. Results were obtained in animals from experiment 2 (Table 1). (a to c) Antibody titers for peptide 1L15 (a) peptide 7L15 (b), and CPV (c), as measured by an ELISA performed as described in the legend to Fig. 1. (d to i) T-cell proliferation expressed as stimulation indices for cells incubated with KLH (d), KLH-peptide conjugate (equal amounts of KLH-1L15 and KLH-7L15) (e), CPV antigen (f), peptide 1L15 (g), peptide 7L15 (h), and a control peptide (representing sequence positions 570 to 584 of VP2) (i). Stippled bars indicate samples taken after challenge. Experimental stages: A, before vaccination; B, 70 days after vaccination; C, $9 \mathrm{dpi}$; D, $30 \mathrm{dpi}$; and E, $90 \mathrm{dpi}$. PBMC in stages A to $\mathrm{D}$ had been stored frozen, and cells in stage $\mathrm{E}$ were directly used after isolation. For more details, see Materials and Methods. 


\section{naturally infected \\ vaccinated with peptide \\ MS D G A V Q P D G G Q A VRNERAT}

FIG. 4. Core of amino acid sequence of antigenic site bound by antibodies in neutralizing sera from dogs vaccinated with the synthetic vaccine and from previously described (27) naturally infected dogs. The amino-terminal 21 residues of VP2 are outlined. Core sequences mapped with PEPSCAN are boxed.

VP2 to which the antipeptide antibodies were directed is a flexible site (57), which will allow induced fit during antibody binding. (ii) The N-terminal domain of VP2 is of functional importance for the virus (58). (iii) A limited proportion of the approximately $50 \mathrm{VP} 2 \mathrm{~N}$ termini in the viral capsid are exposed so that only one or a few antibody molecules per virion are needed to neutralize the virus $(10,27)$. (iv) The $\mathrm{N}$ terminus of VP2 is a conserved domain in the different isolates from dogs, cats, minks, and raccoons $(33,37,42,43)$.

CPV contains more than one site for neutralization. With murine monoclonal antibodies, several neutralization sites have been localized on the viral surface $(8,27,30,37,44)$. For the target animals, there is now also evidence for the existence of multiple neutralization sites on CPV, based on the blocking studies with the neutralizing dog sera and peptides (Table 2). The peptide used in this study does not appear to be part of an immunodominant site. This leads us to speculate about the potential of the vaccine for induction of immunity in the presence of antivirus antibodies (see below).

After challenge, the vaccinated dogs undergo a subclinical CPV infection, which is probably the result of very limited abortive viral replication. This is based on the following observations: seroconversion occurred within $10 \mathrm{dpi}$ in $\mathrm{HI}$ and neutralization blocking assays, body temperature was elevated in a number of animals at 5 or $6 \mathrm{dpi}$, and some fecal samples at 5 dpi contained a very low level of CPV antigen (Tables 2 and 3; Fig. 2 to 4 ). Such effects were expected. Animals vaccinated with inactivated CPV excrete some virus after challenge, even if they had already a low level of preexisting anti-CPV antibodies (18). Even when compared with other studies $(2,39)$, the challenge we used was extraordinarily devastating for the SPF control animals. Nevertheless, vaccinated animals were fully protected against disease, which proves the efficacy of this peptide vaccine.

The protection obtained in our experiments seems to be mediated by antipeptide antibodies (i.e., directed against the $\mathrm{N}$ terminus of VP2), while T-cell responses hardly play a role at the time of infection. The T-cell epitopes involved appeared to be localized not in the peptides but within the carrier protein KLH. Thus, the protection of the dogs by vaccination with the peptide vaccine must have proceeded through the humoral immune system in accordance with other studies using antibodies directed against whole CPV $(34,36,39)$.

An advantage of the peptide vaccine described in this report is the possibility of designing tests which discriminate between vaccinated and infected animals. With the HI test, animals which had been infected with virus could be distinguished from vaccinated animals before experimental infection (Table 3 ). Alternative tests could obviously be developed, as is evident from the blocking experiments, in which antibody binding could be inhibited by the peptides used for vaccination only in the sera taken before seroconversion (Table 2). Such discriminatory tests are useful in programs to eradicate pathogenic viruses like that applied with the veterinary marker vaccine for pseudorabies virus infection in swine (59). They can also be of importance in the surveillance of the occurrence of a virus, for which vaccination with peptides might become available.

Another advantage of the synthetic peptide vaccine over classical vaccines is its potential to overcome the nonresponsiveness to vaccination in young animals that is caused by the presence of small residual amounts of maternal antibodies which neutralize the live attenuated viruses used in conventional vaccines. Conventional vaccination against CPV in puppies younger than 10 weeks of age does not guarantee protection because they have maternally derived antibodies (40), which were raised against whole virus. If the antibodies against the peptide antigens of CPV are not among the maternally derived antibodies, the peptide vaccine would allow triggering of the immune system in the neonate at a much earlier stage than is possible under present conditions. Our PEPSCAN data suggest that indeed among the antibodies directed against whole virus in infected control animals, the antipeptide antibodies are probably not present.

Our results show for the first time that a peptide vaccine is just as efficacious as the classical vaccine prepared from whole virus. The question arises whether this approach also applies to other pathogens. Since CPV is a DNA virus, we speculate that at least for those viruses with low mutation rates, the minimal requirements for full protection might be less stringent than for RNA viruses. Because of this and the high homology between the host range variants of CPV, feline panleukopenia virus, mink enteritis virus, and raccoon parvovirus, we expect that cats, minks, and raccoons will be equally well protected when given a similar peptide vaccine. Furthermore, it is likely that this approach is applicable for other parvoviruses for which vaccination is desirable such as porcine parvovirus and human B19 parvovirus $(3,31)$. It was recently shown that a recombinant B19 capsid peptide with the amino acid sequence of the $\mathrm{N}$ terminus of VP2 also induced neutralizing antibodies (48), indicating that this domain is a general site for neutralization in autonomously replicating parvoviruses. The fact that it is a synthetic peptide or recombinant B19 capsid peptide may be of interest for vaccination of humans. If the properties of flexibility and limited exposure provide clues for obtaining protective antipeptide antibodies, other DNA viruses and small nonenveloped viruses should receive renewed attention for a similar approach in preparing a synthetic vaccine. Therefore, it is important to know how the $\mathrm{N}$ terminus of VP2 functions during CPV infection and whether other viral entities share analogous domains which could be the subject for vaccine development.

In conclusion, we have shown that the synthetic vaccine for immunization of dogs against CPV is acceptable and feasible as well, because it was very effective under unusually heavy conditions of challenge.

\section{ACKNOWLEDGMENTS}

This work was carried out as a collaborative project between Inmunologia y Genetica Aplicada S.A., State Veterinary Institute for Virus Research, and Institute for Animal Science and Health in a BRIDGE program (BIOT-CT91-0256) funded by the European Economic Community.

We thank Gerard van de Wetering, Ronald Boshuizen, Trudie Mooij, Drohpatie Parohi, Jan Groen, and Heinz Broeders for technical assistance with immunochemical tests; Norbert Stockhofer-Zurwieden for histologic examination of organ tissues; H. B. Oonk for reading the manuscript; the personnel of the animal care units at the Institute for Animal Science and Health (ID-DLO) (previously the Central Veterinary Institute [CDI-DLO]) at Lelystad and at the National Institute for Public Health and Environmental Protection RIVM at Bilthoven 
for assistance in the animal experiments; and Janke de Jager-Koning for typing the manuscript.

\section{REFERENCES}

1. Agbandje, M., R. McKenna, M. G. Rossmann, M. L. Strassheim, and C. R. Parrish. 1993. Structure determination of feline panleukopenia virus empty particles. Proteins Struct. Funct. Genet. 16:155-171.

2. Appel, M., F. W. Scott, and L. R. Carmichael. 1979. Isolation and immunization studies of a canine parvoviruslike virus from dogs with haemorrhagic enteritis. Vet. Rec. 105:156-159.

3. Bansal, G. P., J. A. Hatfield, F. E. Dunn, A. A. Kramer, F. Brady, C. H. Riggin, M. S. Collett, K. Yoshimoto, S. Kajigaya, and N. S. Young. 1993. Candidate recombinant vaccine for human B19 parvovirus. J. Infect. Dis. 167:1034-1044.

4. Benjamini, E., J. V. Torres, L. L. Werner, and A. Malley. 1991. Isolation and characterization of the neutralizable epitope of simian retrovirus-1 (SRV-1) and of the cell receptor for the virus. Adv. Exp. Med. Biol. 303:71-77.

5. Bittle, J. L., R. A. Houghten, H. Alexander, T. M. Shinnick, J. G. Sutcliffe, R. A. Lerner, D. J. Rowlands, and F. Brown. 1982. Protection against foot and mouth disease by immunization with a chemically synthesized peptide predicted from the viral nucleotide sequence. Nature (London) 298:30-33.

6. Bjorling, E., K. Broliden, D. Bernardi, G. Utter, R. Thorstensson, F. Chiodi, and E. Norrby. 1991. Hyperimmune antisera against synthetic peptides representing the glycoprotein of human immunodeficiency virus type 2 can mediate neutralization and antibodydependent cytotoxic activity. Proc. Natl. Acad. Sci. USA 88:60826086.

7. Carmichael, L. E., J. C. Joubert, and R. V. H. Pollock. 1980. Hemagglutination by canine parvovirus: serologic studies and diagnostic applications. Am. J. Vet. Res. 41:784-791.

8. Chapman, M. S., and M. G. Rossmann. 1993. Structure, sequence and function correlations among parvoviruses. Virology 194:491508.

9. Coffin, J. M. 1990. Genetic variation in retroviruses. Appl. Virol. Res. 2:11-33.

10. Cortés, E., C. San Martin, J. Langeveld, R. Meloen, K. Dalsgaard, C. Vela, and J. I. Casal. 1993. Topographical analysis of canine parvovirus virions and recombinant VP2 capsids. J. Gen. Virol. 74:2005-2010.

11. Coste, J., D. Le-Nguyen, and B. Castro. 1990. PyBOP: a new peptide coupling reagent devoid of toxic by-product. Tetrahedron Lett. 31:205-208.

12. Cotmore, S. F., and P. Tattersall. 1987. The autonomously replicating parvoviruses of vertebrates. Adv. Virus Res. 33:91-174.

13. Dalsgaard, K. 1974. Saponin adjuvants. III. Isolation of a substance from Quillaja saponaria Molina with adjuvant activity in foot-and-mouth disease vaccines. Arch. Gesamte Virusforsch. 44:243-254.

14. Dietzschold, B., M. Gore, D. Marchadier, H.-S. Niu, H. M. Bunschoten, L. Otvos, Jr., W. H. Wunner, H. C. J. Ertl, A. D. M. E. Osterhaus, and H. Koprowski. 1990. Structural and immunological characterization of a linear virus-neutralizing epitope of the rabies virus glycoprotein and its possible use in a synthetic vaccine. J. Virol. 64:3804-3809.

15. DiMarchi, R., G. Brooke, C. Gale, V. Cracknell, and N. Mowat. 1986. Protection against foot and mouth disease by a synthetic peptide. Science 232:639-641.

16. Doel, T. R., C. Gale, C. M. C. F. Do Amaral, G. Mulcahy, and R. Dimarchi. 1990. Heterotypic protection induced by synthetic peptides corresponding to three serotypes of foot-and-mouth disease virus. J. Virol. 64:2260-2264.

17. Domingo, E., M. G. Mateu, M. A. Martínez, J. Dopazo, A. Moya, and F. Sobrino. 1990. Genetic variability and antigenic diversity of foot-and-mouth disease virus. Appl. Virol. Res. 2:233-266.

18. Eugster, A. K. 1980. Studies on canine parvovirus infection: development of an inactivated vaccine. Am. J. Vet. Res. 41:20202024.

19. Fields, C. G., D. H. Lloyd, R. L. Macdonald, K. M. Otteson, and R. L. Noble. 1991. HBTU activation for automated Fmoc solidphase peptide synthesis. Pept. Res. 4:95-101.
20. Geerligs, H. J., C. H. Kocken, J. W. Drijfhout, W. J. Weijer, W. Bloemhoff, J. B. Wilterdink, G. W. Welling, and S. Welling-Wester. 1990. Virus neutralizing activity induced by synthetic peptides of glycoprotein D of herpes simplex virus type 1, selected by their reactivity with hyperimmune sera from mice. J. Gen. Virol. 71:1767-1774.

21. Goudsmit, J., N. K. T. Back, and P. L. Nara. 1991. Genomic diversity and antigenic variation of HIV-1: links between pathogenesis, epidemiology and vaccine development. FASEB J. 5:2427-2436.

22. Hunt, A. R., W. A. Short, A. J. Johnson, R. A. Bolin, and J. T. Roehrig. 1991. Synthetic peptides of the E2 glycoprotein of Venezuelan equine encephalomyelitis virus. II. Antibody to the amino terminus protects animals by limiting viral replication. Virology 185:281-290.

23. Javaherian, K., A. J. Langlois, G. J. LaRosa, A. T. Profy, D. P. Bolognesi, W. C. Herlihy, S. D. Putney, and T. J. Matthews. 1990. Broadly neutralizing antibodies elicited by the hypervariable neutralizing determinant of HIV-1. Science 250:1590-1593.

24. Kinnunen, L., A. Huovilainen, T. Pöyry, and T. Hovi. 1990. Rapid molecular evolution of wild type 3 poliovirus during infection in individual hosts. J. Gen. Virol. 71:317-324.

25. Kit, M., S. Kit, S. P. Little, R. D. Di Marchi, and C. Gale. 1991. Bovine herpesvirus-1 (infectious bovine rhinotracheitis virus)based viral vector which expresses foot-and-mouth disease epitopes. Vaccine 9:564-572.

26. Koolen, M. J. M., M. A. J. Borst, M. C. Horzinek, and W. J. M. Spaan. 1990. Immunogenic peptide comprising a mouse hepatitis virus A59 B-cell epitope and an influenza virus T-cell epitope protects against lethal infection. J. Virol. 64:6270-6273.

26a.Langeveld, J. P. M., J. I. Casal, E. Cortés, G. van de Wetering, R. Boshuizen, W. M. M. Schaaper, K. Dalsgaard, and R. H. Meloen. Effective induction of neutralizing antibodies with the amino terminus of VP2 of canine parvovirus as a synthetic peptide. Vaccine, in press.

27. Langeveld, J. P. M., J. I. Casal, C. Vela, K. Dalsgaard, S. H. Smale, W. C. Puijk, and R. H. Meloen. 1993. B-cell epitopes of canine parvovirus: distribution on the primary structure and exposure on the viral surface. J. Virol. 67:765-772.

28. Lerner, R. A., N. Green, H. Alexander, F.-T. Liu, J. G. Sutcliffe, and T. M. Shinnick. 1981. Chemically synthesized peptides predicted from the nucleotide sequence of the hepatitis B virus genome elicit antibodies reactive with the native envelope protein of Dane particles. Proc. Natl. Acad. Sci. USA 78:3403-3407.

29. López de Turiso, J. A., E. Cortés, C. Martinez, R. Ruiz de Ybánez, I. Simarro, C. Vela, and J. I. Casal. 1992. Recombinant vaccine for canine parvovirus in dogs. J. Virol. 66:2748-2753.

30. López de Turiso, J. A., E. Cortés, J. Ranz, J. García, A. Sanz, C. Vela, and J. I. Casal. 1991. Fine mapping of canine parvovirus B cell epitopes. J. Gen. Virol. 72:2445-2456.

31. Martínez, C., K. Dalsgaard, J. A. López de Toriso, E. Cortés, C. Vela, and J. I. Casal. 1992. Production of porcine parvovirus empty capsids with high immunogenic activity. Vaccine 10:684690.

32. Martínez, M. A., J. Dopazo, J. Hernández, M. G. Mateu, F. Sobrino, E. Domingo, and N. J. Knowles. 1992. Evolution of the capsid protein genes of foot-and-mouth disease virus: antigenic variation without accumulation of amino acid substitutions over six decades. J. Virol. 66:3557-3565.

33. Martyn, J. C., B. E. Davidson, and M. J. Studdart. 1990. Nucleotide sequence of feline panleukopenia virus: comparison with canine parvovirus identifies host-specific differences. J. Gen. Virol. 71:2747-2753.

34. Meunier, P. C., B. J. Cooper, M. J. G. Appel, M. E. Launieu, and D. Slauson. 1985. Pathogenesis of canine parvovirus enteritis: sequential virus distribution and passive immunization studies. Vet. Pathol. 22:617-624.

35. Muir, S., J. P. Weintroub, J. Hogle, and J. L. Bittle. 1991. Neutralizing antibody to Mengo virus, induced by synthetic peptides. J. Gen. Virol. 72:1087-1092.

36. Parrish, C. R. 1990. Emergence, natural history, and variation of canine, mink, and feline parvoviruses. Adv. Virus Res. 38:403-450.

37. Parrish, C. R., C. F. Aquadro, and L. E. Carmichael. 1988. Canine 
host range and a specific epitope map along with variant sequences in the capsid protein gene of canine parvovirus and related feline, mink and raccoon parvoviruses. Virology 166:293-307.

38. Pavlov, A. V., S. S. Rybakov, V. M. Ivaniushchenkov, A. V. Chepurkin, V. N. Petrov, N. N. Driagalin, and A. N. Burdov. 1991. Protection from foot-and-mouth disease virus in naturally-susceptible animals by a linear polymer of a synthetic peptide. Bioorg. Khim 17:953-963.

39. Pollock, R. V. H. 1982. Experimental canine parvovirus infection in dogs. Cornell Vet. 72:103-119.

40. Pollock, R. V. H., and L. E. Carmichael. 1982. Maternally derived immunity to canine parvovirus infection: transfer, decline and interference with vaccination. J. Am. Vet. Med. Assoc. 180:37-42.

41. Posthumus, W. P. M., J. A. Lenstra, A. P. van Nieuwstadt, W. M. M. Schaaper, B. A. M. van der Zeijst, and R. H. Meloen. 1991. Immunogenicity of peptides simulating a neutralization epitope of transmissible gastroenteritis virus. Virology 182:371375 .

42. Reed, A. P., E. V. Jones, and T. J. Miller. 1988. Nucleotide sequence and genome organization of canine parvovirus. J. Virol. 62:266-276.

43. Rhode, S. L., III. 1985. Nucleotide sequence of the coat protein gene of canine parvovirus. J. Virol. 54:630-633.

44. Rimmelzwaan, G. F., J. Carlson, F. G. C. M. UytdeHaag, and A. D. M. E. Osterhaus. 1990. A synthetic peptide derived from the amino acid sequence of CPV structural proteins, which defines a $B$ cell epitope and elicits antiviral antibody in Balb/c mice. J. Gen. Virol. 71:2741-2745.

45. Rimmelzwaan, G. F., J. Groen, H. Egberink, G. H. A. Borst, F. G. C. M. UytdeHaag, and A. D. M. E. Osterhaus. 1991. The use of enzyme-linked immunosorbent assay systems for serology and antigen detection in parvovirus, coronavirus, and rotavirus infections in dogs in The Netherlands. Vet. Microbiol. 26:25-40.

46. Rimmelzwaan, G. F., N. Juntti, B. Klingeborn, J. Groen, F. G. C. M. UytdeHaag, and A. D. M. E. Osterhaus. 1990. Evaluation of enzyme-linked immunosorbent assays based on monoclonal antibodies for the serology and antigen detection in canine parvovirus infections. Vet. Q. 12:14-20.

47. Rink, H. 1987. Solid-phase synthesis of protected peptide fragments using a trialkoxy-diphenyl-methyl ester resin. Tetrahedron Lett. 28:3787-3790.

48. Saikawa, T., S. Anderson, M. Momoeda, S. Kajigaya, and N. S. Young. 1993. Neutralizing epitopes of B19 parvovirus cluster in the VP1 unique and VP1-VP2 junction regions. J. Virol. 67:30043009 .

49. Saliki, J. T., B. Mizak, H. P. Flore, R. R. Gettig, J. P. Burand, L. E.
Carmichael, H. A. Wood, and C. R. Parrish. 1992. Canine parvovirus empty capsids produced by expression in a baculovirus vector: use in analysis of viral properties and immunization of dogs. J. Gen. Virol. 73:369-374.

50. Shafferman, A., P. B. Jahrling, R. E. Benveniste, M. G. Lewis, T. J. Phipps, F. Eden-McCutchan, J. Sadoff, G. A. Eddy, and D. S. Burke. 1991. Protection of macaques with a simian immunodeficiency virus envelope peptide vaccine based on conserved human immunodeficiency virus type 1 sequences. Proc. Natl. Acad. Sci. USA 88:7126-7130.

51. Siegl, G., R. C. Bates, K. I. Berns, B. J. Carter, D. C. Kelly, E. Kurstak, and P. Tattersall. Characteristics and taxonomy of Panoviridae. Intervirology 23:61-73.

52. Snijders, A., B. J. Benaissa-Trouw, T. A. Oosterlaken, W. C. Puijk, W. P. Posthumus, R. H. Meloen, W. A. Boere, J. D. Oosting, C. A. Kraaijeveld, and H. Snippe. 1991. Identification of linear epitopes on Semliki Forest Virus E2 membrane protein and their effectiveness as a synthetic peptide vaccine. J. Gen. Virol. 72:557-565.

53. Steinhauer, D. A., and J. J. Holland. 1987. Rapid evolution of RNA viruses. Annu. Rev. Microbiol. 41:409-433.

54. Tanaka, Y., L. Zeng, H. Shiraki, H. Shica, and H. Tozawa. 1991. Identification of a neutralization epitope on the envelope gp46 antigen of human $T$ cell leukemia virus type $I$ and induction of neutralizing antibody by peptide immunization. J. Immunol. 147: 354-360.

55. Trirawatanapong, T., B. Chandran, R. Putnak, and R. Padmanabhan. 1992. Mapping of a region of dengue virus type-2 glycoprotein required for binding by a neutralizing monoclonal antibody. Gene 116:139-150.

56. Trudel, M., F. Nadon, C. Sequin, and H. Binz. 1991. Protection of BALB/c mice from respiratory syncytial virus infection by immunization with a synthetic peptide derived from the G glycoprotein. Virology 185:749-757.

57. Tsao, J., M. S. Chapman, M. Agbandje, W. Keller, K. Smith, H. Wu, M. Luo, T. J. Smith, M. G. Rossmann, R. W. Compans, and C. R. Parrish. 1991. The three-dimensional structure of canine parvovirus and its functional implications. Science 251:1456-1464.

58. Tullis, G. E., L. R. Burger, and D. J. Pintel. 1992. The trypsin sensitive RVER domain in the capsid proteins of minute virus of mice is required for efficient cell binding and viral infection but not for proteolytic processing in vivo. Virology 191:846-857.

59. Van Oirschot, J. T., A. L. J. Gielkens, R. J. M. Moormann, and A. J. M. Berns. 1990. Marker vaccines, virus protein-specific antibody assays and the control of Aujeszky's disease. Vet. Microbiol. 23:85-101. 